编者按: 为了深入落实全国教育大会和新时代全国高等学校本科教育工作会议精神, 推动新工科、新医科、新农科、 新文科建设, 教育部 2019 年启动了一流本科专业建设 “双万计划”: 2019-2021 年面向各类高校和全部专业, 建设 10000 个左右国家级一流本科专业点和 10000 个左右省级一流本科专业点。目的是通过一流专业建设, 带动高校优 化专业结构、促进专业建设质量提升、形成高水平人才培养体系, 实现高等教育内涵式发展, 支撑教育强国建设。 教育部 2019 年 12 月公布了首批国家级一流专业建设点。

为了进一步推进化学类专业一流建设, 2018-2022 年教育部高等学校化学类专业教学指导委员会与《大学化学》 编辑部协商决定出版 “化学类专业一流建设” 专刊, 刊登教育部相关文件精神解读、一流专业建设经验和一流专业 申报注意事项等论文, 以指导、示范和引领化学类专业的一流建设。因篇幅有限, 本专刊仅精选出 33 篇论文集结发 表, 其中教育部相关文件精神解读论文 1 篇、一流专业建设经验介绍论文 24 篇(其中综合类院校 12 篇, 师范类院校 6 篇, 理工类院校 6 篇), 以及具体案例类论文 8 篇。希望这些论文能对广大高校的一流专业建设和申报提供有益借鉴。

\title{
高等学校化学类本科一流专业建设标准和建设重点浅析
}

张树永 $1{ }^{*}$, 朱亚先 ${ }^{2}$

1 山东大学化学与化工学院, 济南 250100

2 厦门大学化学化工学院, 福建 厦门 361005

摘要：一流专业建设是支撑一流本科、一流高校建设的基础。本文结合教育部一流专业申报, 分析了一流专业建设 标准和建设重点, 并对一流专业建设过程中应该注意的关键性问题进行了说明, 对今后一流专业建设具有一定的指 导意义。

关键词: 本科专业; 一流专业; 建设标准; 建设重点

中图分类号: G64; O6

\section{Brief Analysis on the Standard and Key Points of Construction of First-Class Majors of Higher Chemistry Education}

\author{
Shuyong Zhang ${ }^{1,{ }^{*}}$, Yaxian Zhu ${ }^{2}$ \\ ${ }^{1}$ School of Chemistry and Chemical Engineering, Shandong University, Jinan 250100, China. \\ ${ }^{2}$ College of Chemistry and Chemical Engineering, Xiamen University, Xiamen 361005, Fujian Province, China.
}

\begin{abstract}
The construction of first-class major is the foundation for constructing the first-class undergraduate education and world-leading university. This paper clarifies the construction standard and key points of first-class major on the analysis of the Information Tables for application of the first-class major. Some suggestions for the future construction of firs-class major are provided. It is of certain guiding significance to the construction of the first-class major in the future.
\end{abstract}

Key Words: Undergraduate majors; Firs-class majors; Construction standard; Key points for construction 
十九大召开标志着我国改革开放进入新时代。习近平同志指出 “我们比历史上任何时期都更需 要建设世界科技强国! [1]”。要建设科技强国必须有一流人才做支撑; 要培养一流人才必须有一流本 科教育做支撑。为此, 习近平同志要求 “引导各类高校发挥办学优势, 在不同领域各展所长, 建设 优势特色专业, 提高创新型、复合型、应用型人才培养质量” ${ }^{[2]}$, 教育部也发出了 “做强一流本科、

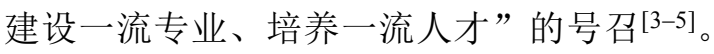

专业是高校人才培养的基本单元。建设一大批能够代表我国水平、参与国际竞争的一流专业, 应 该成为各层次高校共同努力的目标。本文针对一流专业建设的思路与重点进行分析, 希望为一流专 业建设提供借鉴。

\section{1 对一流专业建设标准的认识}

目前, 部分高校对如何建设一流专业还存在一些模糊甚至错误的认识 ${ }^{[6]}$, 为此, 必须首先明确 一流专业的建设标准。关于一流专业建设标准目前尚缺乏统一明确的表述, 可以从以下三方面理解 并进行概括。

首先, “只有培养出一流人才的高校才能成为世界一流大学” [7]。可以说培养一流人才是判断高 校和专业是否一流的根本标准, 但不同类型的高校对一流人才的理解并不相同。这表明, 研究型、 地方性、行业性、应用型高校都可以在不同赛道上走出特色发展之路, 建设一流专业、培养一流人 才。这恰恰是分类指导、分类建设的学理基础 ${ }^{[8,9]}$ 。

其次, 教育部明确指出国家一流专业必须通过专业认证 ${ }^{[4]}$, 这表明专业认证标准是制订一流专 业建设标准的主要依据。工程专业 ${ }^{[6,10]}$ 、医学专业 ${ }^{[6,11]}$ 和师范专业 ${ }^{[6,12]}$ 的认证标准均已发布, 而与化 学类专业有关的标准只有《普通高等学校本科专业类教学质量国家标准》(以下简称《国标》) ${ }^{[13]}$, 其基本办学条件构成一级认证标准(保合格), 《国标》的整体可以作为二级认证标准(上水平)。虽然 《国标》达不到一流专业(追卓越)建设标准 ${ }^{[14-16]}$, 但由于不少专业尚未全面满足《国标》的要求, 故 《国标》对一流专业建设仍具有指导意义。

第三, 教育部在《关于做好国家级一流本科专业建设有关工作的通知》中提出, 一流专业要 “定 位明确、管理规范、师资力量雄厚、改革成效突出、培养质量一流” (见表1)。其中, 专业定位准确 是指能够适应国家或区域经济社会发展需要, 符合学校发展定位和培养目标, 学生就业发展方向和 层次明确; 专业管理规范是指符合国标 ${ }^{[13]}$ 要求, 人才培养方案科学合理, 教育教学管理制度健全、 执行有效; 改革成效突出则强调以先进的教育理念, 持续深化教育教学改革, 不断创新教学内容和 教学方法手段, 取得显著成绩; 师资力量雄厚要求专业教学队伍数量适宜、结构合理, 广泛开展教 育教学研究, 整体教学水平高; 培养质量一流要求体现以学生为中心, 促进学生全面发展, 学生就 业发展符合预期, 得到毕业生和用人单位的普遍认可。相关要求在《国家级一流本科专业建设点信 息采集表》(以下简称《采集表》) 中有比较全面的体现。

综合以上认识并结合表 1 的分析, 我们可以将一流专业建设标准归纳为: 一流教育理念、一流办 学定位、一流建设积累、一流教学条件、一流师资队伍、一流课程教学、一流教学管理、一流质量 保障和一流人才培养成效等 9 个 “一流” 。其中, 一流建设积累和一流人才培养成效是一流专业建设 的结果，而其他七个方面则是未来一流专业建设的重点。

分析专业建设现状发现, 当前一流专业申报和建设存在的主要问题包括: 办学定位与人才培养 目标不明确、不准确; 人才培养目标落实不到位; 改革不能结合当前的形势与要求; 师资队伍建设 以及教师的教学理念、教学方法相对滞后; 不能依据目标导向、问题导向的要求对人才培养进行系 统的思考和设计; 办学条件、课程体系、教学内容不适应培养一流人才的需要; 不注重质量评价和 持续改进; 缺乏特色发展、优势发展理念等 ${ }^{[9,17,18]}$ 。 
大学 化 学 Univ. Chem. 2021, 36(5), 2012036 (3 of 6)

表1 一流专业建设涉及的主要核心指标及与《采集表》的对应关系

\begin{tabular}{|c|c|c|c|}
\hline 一级指标 & 二级指标 & 评审要求 & 《采集表》对应表格 \\
\hline \multirow[t]{4}{*}{ 1. 办学定位 } & 1.1 办学定位 & 专业定位明确 & 5. 专业定位(建设一流专业) \\
\hline & 1.2 培养目标 & & \\
\hline & 1.3 培养理念 & & 1. 专业基本情况(教授上课率、实验实践占比) \\
\hline & & & 6. 深化专业综合改革(学生中心、产出导向、持续改进) \\
\hline \multirow[t]{9}{*}{ 2. 办学条件 } & 2.1 办学积累 & & 5. 历史沿革 \\
\hline & 2.2 师资条件 & 师资力量雄厚 & 2. 专业负责人基本情况(能否引领一流建设) \\
\hline & & & 7. 加强师资队伍建设 \\
\hline & 2.3 教学条件 & & 4. 近3年本专业获省部级及以上奖励和支持情况 \\
\hline & & & 6. 深化专业综合改革 \\
\hline & 2.4 教学管理 & 专业管理规范 & 6. 深化专业综合改革 \\
\hline & & & 7. 基层教学组织建设 \\
\hline & & & 8. 专业教学质量保障体系建设 \\
\hline & 2.5 教风学风 & & (近三年未出现重大安全责任事故) * \\
\hline \multirow[t]{10}{*}{ 3. 办学效果 } & 3.1 改革成效 & 改革成效突出 & 3. 近3年本专业毕业生就业(升学)情况 \\
\hline & & & 4. 近3年本专业获省部级及以上奖励和支持情况 \\
\hline & & & 5. 特色优势 \\
\hline & & & 6. 深化专业综合改革的主要成效 \\
\hline & & & 7. 加强师资队伍和基层教学组织建设的主要成效 \\
\hline & & & 8. 加强专业教学质量保障体系建设的主要成效 \\
\hline & 3.2 毕业生 & 培养质量一流 & 3. 近3年本专业毕业生就业(升学)情况 \\
\hline & & & 8. 专业教学质量保障体系建设(毕业生调查) \\
\hline & 3.3 社会声誉 & & 8. 专业教学质量保障体系(用人单位调查) \\
\hline & 3.4 特色示范 & & 5. 特色优势 \\
\hline
\end{tabular}

*一票否决

\section{2 一流专业建设的工作要点}

要规划好建设好一流专业, 必须坚持目标导向和问题导向, 找准与一流标准的差距和制约一流 人才培养的关键问题，及时补足短板。

\section{1 一流办学定位}

与一般专业需要综合考虑学科数量和水平、师资队伍数量和水平、办学条件、招生数量和水平、 毕业生成长情况、学校历史积淀和校风、社会认可程度等确定办学定位不同 ${ }^{[17,19]}$, 一流专业建设点 的定位相对明确, 如表2所示。

表2 国家级一流专业建设点的办学定位

\begin{tabular}{ccc}
\hline 国际 & 国内 & 省区 \\
\hline 国际一流 & 国内一流 & 省区一流 \\
国际特色一流 & 国内特色一流 & 省区特色一流 \\
国际知名 & 国内知名 & 省区知名 \\
\hline
\end{tabular}


其中, 中央赛道高校应该定位国内一流国际知名、国际特色一流或国际一流; 省级赛道高校可 以定位省区一流国内知名、国内特色一流或者国内一流。所谓特色一流通常是指专业在地域(物产、 民族等)、行业(农林、地矿、师范等)、学科方向、办学理念(高端化、国际化、复合型、创新创业等)、 服务面向(高端引领、中层骨干、乡村、中西部、边疆等)等方面不同于其他同类和同水平专业, 具有 一定示范引领意义的方面 ${ }^{[8,19]}$ 。

在一流专业建设过程中, 各专业必须以一流为目标进行系统设计, 使一流理念在培养方案、支 撑条件和人才培养达成度考核方面得到全方位的体现和落实。

\section{2 一流教育理念}

一流教育理念可以概括为 “一三一理念” , 即 “一个中心、三个导向、一个改进”, 具体包括 “学生中心(student centeredness)” “目标导向 (objective-based education)” “问题导向 (problemorientation)” “产出导向(outcome-based evaluation, OBE)” 和 “持续改进(continuous improvement)” ${ }^{[14,20]}$ 。

在根据 “目标导向” 确定专业办学定位和人才培养目标后, 需要根据 “学生中心” “产出导向” 的要求系统设计培养方案, 实施综合改革和建设, 保证毕业要求的全面落实和达成; 要坚持 “问题 导向” 和 “持续改进” 理念, 通过构建全流程闭环的教学质量保障机制, 针对培养方案、课程大纲、 课程设计、课堂教学、办学条件、学生指导服务等开展周期性评估, 特别是定期针对毕业生和用人 单位, 基于OBE理念围绕毕业要求达成度开展系统调研, 并对调研结果进行分析判断, 形成持续提 升培养目标达成度和人才培养满意度的机制。

应注意培养方案与课程体系的不同, 培养方案包含课程体系、实验和实践教学体系、课外拓展 体系等, 是对与学生培养相关的课内外、校内外乃至境内外所有的教育教学活动进行的整体设计, 体现全员全过程全方位育人理念 ${ }^{[16]}$ 。

\section{3 一流教学条件}

建设一流办学条件是培养一流人才的重要基础。作为一流专业, 除了必须满足《国标》规定的 硬件条件(合格标准)外, 还必须根据一流人才培养需要, 规划和建设与人才培养定位相适应的教学 软硬件条件 ${ }^{[6]}$ 。除了学校的公共办学条件必须满足人才高端培养的基本需求外, 专业还必须建立符 合人才培养定位和特色培养要求的师资队伍、教室和实验室、仪器设备、图书资料、课程教学资源、 信息化条件和资源、实习实践基地和创新创业条件等硬件条件, 一流课程和一流教材建设也包含在 一流条件建设之中; 另外, 还需要建立适应一流人才培养的文化氛围、教学学风、管理规章制度、 实验室和科研平台开放与管理、协同育人机制和国际化教学等软条件, 并保证必要的经费投入。

\section{4 一流师资队伍}

师资队伍的数量、结构、水平和能力是专业建设的最重要支撑 ${ }^{[8,17,18]}$ 。教师数量的合格标准在《国 标》中有明确规定。应该注意的是, 不同类型高校对一流师资建设的要求存在显著差异: 对于研究 型大学, 应更多地关注教师学术水平和研究能力以及科教协同育人机制建设; 对于应用型高校, 则 应更多地关注教师企业/实务部门工作经历、 “双师型” 队伍建设情况 ${ }^{[18]}$, 高校和企事业单位交流挂 职和互聘机制建设, 以及行业专家和领军人才广泛参与培养方案修订、课程和实践教学以及创新创 业和毕业论文(设计)指导等。

在一流师资建设过程中, 师资队伍的数量和结构固然重要, 但教师在教学研究和教学建设中的 投入及其成效更为重要。在一流专业建设过程中必须突出政策引导, 吸引教师将更多的时间和精力 投入本科教学研究、教学建设和教学工作, 同时应突出教师教学发展机制建设和运行 ${ }^{[17]}$, 突出基层 教学组织的建设及运行。就目前而言, 学院和专业的教师发展机制和基层教学组织的建设和运行往 往是短板, 因此强化新入职青年教师培养、强化教师终生学习机制建设、强化基层教学组织建设应 成为未来一流专业建设的工作重点之一。明确基层教学组织的组织架构、义务权利、规章制度、活 动组织和活动效果考核, 建立规范的教学管理和教学研究机制, 推进教学团队建设和团队型成果的 培育是加强基层教学组织建设的关键。 


\section{5 一流课程教学}

课程建设和课堂教学是一流专业建设、一流人才培养的逻辑起点。要建设一流专业必须有一流 课程和一流课堂作为支撑。所谓一流课程, 首先其课程教学目标必须是定位一流的, 其次应该用一 流的理念 “一三一” 理念)全面落实毕业要求, 采用一流的教学理念、一流的教学设计、一流的教学 方法和一流的效果考核来保证课程教学达到一流的教学效果。在一流的理念中应包含以学生发展为 中心、产出导向教学和评价、课程思政和全方位育人等内容。关于一流课程的 “两性一度” 标准及 其落实途径, 在相关文献中已有详细解读, 此处不再赘述 ${ }^{[18]}$ 。

\section{6 一流教学管理}

一流的教学管理和质量保障机制建设是推进专业治理体系和治理能力现代化的关键, 也是建好 一流专业的根本保障 ${ }^{[19]}$ 。学校层面的教学管理体制机制建设固然重要, 但一流专业还必须建立符合 自身培养需要的规章制度, 主要包括学生选拔与综合评价、学生学业指导、学生管理、学生助学机 制、导师制管理、基层教学组织建设与运行、教学质量评价与反馈改进、毕业生及用人单位调研、 培养方案评价与修订、教学管理和教师教学激励等。制度和机制建设是专业综合改革和未来一流专 业建设的重要内容。需要强调的是, 一流的教学管理绝对不应仅仅关注教学本身, 还需体现在本科 教育发展战略、领导和教师的精力投入、教学资源配置和教学条件建设等方面 ${ }^{[3]}$ 。

\section{7 一流质量保障}

国家一流专业应强化质量意识、质量文化、质量标准体系和质量保障机制的建设和运行。本科 教育质量保障体系通常由质量标准体系、质量监控体系以及反馈和持续改进体系3部分构成。

一流专业的质量标准体系应参照第1部分讨论的标准并结合本校特点制定, 主要包括招生标准、 专业毕业标准、课程标准和课程教学标准等。其中课程和课堂建设标准应明确课程或课堂所需达到 的知识、素质和能力目标, 并应强化课程的思政教育目标和要求 ${ }^{[20]}$ 。

其次, 一流专业应建立系统高效的质量监督保证机制, 大力推进教学质量意识和质量文化建设。 质量保障机制和持续改进机制往往是当前专业建设的最大短板。虽然绝大多数高校都建立了课堂教 学评价机制, 但培养方案评价和专业的校内外认证机制一般都不够健全, 特别是在外部评价机制(包 括毕业生评价、校友评价、用人单位评价、第三方评价和国家专业认证等)建设方面往往存在更多问 题。一方面是缺乏定期评价的机制, 另一方面是评价指标不科学, 缺乏以产出为目标的调研和分析 机制, 很多专业简单地采用就业率、就业对口率、考研率来来代替调研。这种不重视达成度和满意 度的现状必须尽快改变 ${ }^{[21]}$ 。

另外就是反馈整改机制建设, 需要对调研结果进行系统分析, 建立培养目标、毕业要求、课程 教学、教师发展等多方面的改进机制, 形成质量文化, 保证调研的结论能够切实得以落实。

\section{3 结语}

入选一流专业建设点不是专业建设的终点, 而是在新目标、新要求、新平台上开展专业建设的 起点。国家一流专业要求立足世界、力争一流, 因此, 我们必须在分析过去成效与不足的基础上, 按照目标导向和问题导向的理念, 明确具体改革目标, 落实具体举措, 力争通过 3-5年的建设, 使专 业取得可量化、可考核的明显进步。

\section{参 考 文 献}

[1] 习近平. 在中国科学院第十九次院士大会、中国工程院第十四次院士大会上的讲话. [2018-05-28].

http://www.xinhuanet.com/politics/leaders/2018-05/28/c_1122901308.htm

[2] 习近平. 在全国教育大会上的讲话. [2018-09-10]. http://edu.people.com.cn/n1/2018/0911/c1053-30286253.html

[3] 教育部. 教育部关于加快建设高水平本科教育 全面提高人才培养能力的意见. [2018-10-08]. 
http://www.moe.gov.cn/srcsite/A08/s7056/201810/t20181017_351887.html

[4] 教育部办公厅. 关于实施一流本科专业建设 “双万计划” 的通知. [2019-04-04].

http://www.moe.gov.cn/srcsite/A08/s7056/201904/t20190409_377216.html

[5] 吴岩. 中国大学教学, 2017, No. 11, 4 .

[6] 王洪才, 王务均, 陈迎红, 郑飞中, 王健, 刘丽梅. 重庆高教研究, 2020,8 (4), 24.

[7] 习近平. 全国高校思想政治工作会议上的讲话. [2016-12-07]. http://news.cctv.com/2016/12/08/ARTIihpHZs56dGPSnK5b5x5y161208.shtml

[8] 张树永. 中国大学教学, 2014, No. 4, 48 .

[9] 杨少斌, 曹庆年, 米国际, 郝红武, 张广良. 教育现代化, 2019, No. 43, 95 .

[10] 王孙禺, 赵自强, 雷环. 高等工程教育研究, 2014, No. 5, 23 .

[11] 谢阿娜, 王媛媛, 王景超, 鲁曼, 王维民. 高校医学教学研究, 2017, 7 (1), 13.

[12] 路书红, 黎芳媛. 教育发展研究, 2017, No. 22, 65 .

[13] 教育部高等学校教学指导委员会. 普通高等学校本科专业类教学质量国家标准. 北京: 高等教育出版社, $2018: 3$.

[14] 吴岩. 中国大学教学, 2018, No. 12, 4 .

[15] 张树永, 王玉枝, 朱亚先. 中国大学教学, 2017, No. 4, 51 .

[16] 张树永. 中国大学教学, 2015, No. 3, 55 .

[17] 王雪, 王战军. 上海教育评估研究, 2019, No. 5,53

[18] 张树永, 戚明颖, 宋爱新, 李英, 苑世领, 郝京诚. 大学化学, 2021, 36 (1), 2008024.

[19] 王志刚, 杨令平. 中国高校科技, 2020, No. 1-2, 16.

[20] 张婕. 中国教学行政学院学报, 2012, No. 5, 78 .

[21] 李志义. 化工高等教育, 2020, No. 172, 12. 